\title{
Tendências e Desafios da Reciclagem de Embalagens Plásticas
}

\author{
Amélia S. F. Santos, José Augusto M. Agnelli, Sati Manrich \\ 3R-Nrr, DEMa, UFSCar
}

\begin{abstract}
Resumo: No gerenciamento do resíduo sólido urbano (RSU), a reciclagem surge como uma das vias para reduzir os resíduos sólidos aterrados em solo. Os plásticos constituem uma das classes de materiais com menor índice de reciclagem. Neste trabalho, as principais dificuldades encontradas em diversos países para aumentar os índices de reciclagem dos plásticos e as propostas que estão sendo utilizadas para mudar este cenário foram apresentadas. Por último, também foi apresentado um panorama geral sobre as exigências e limitações do retorno do plástico reciclado para alimentos. Este segmento representa todo um nicho de mercado que pode agregar valor e, principalmente, aumentar os índices de reciclagem de modo sustentável desde que haja investimentos em tecnologias inovadoras e economicamente viáveis.
\end{abstract}

Palavras-chave: Resíduo sólido, reciclagem, embalagens de alimentos, plástico.

\section{Trends and Challenges in Recycling Plastic Packages}

Abstract: In the management of municipal solid waste (MSW), recycling emerges as one of the ways to reduce the solid wastes deposited in landfills. Plastics are one of the classes of materials with the lowest recycling index. The present study deals with the main difficulties encountered in different countries to increase plastics recycling and the procedures adopted to change this scenario. Additionally, the general requirements and the restrictions about the use of recycled plastic for food contact are presented. This application represents a whole market share to be explored, which could add value and increase the recycling indexes in a sustainable way, provided that investments in innovative technologies are made.

Keywords: Solid waste, recycling, food packages, plastic.

\section{Aspectos Gerais}

A disposição dos resíduos sólidos urbanos apresenta problemas relacionados à instalação adequada dos mesmos, ao espaço físico ocupado pelos rejeitos e à proliferação de doenças para parte da população que mora próximo e sobrevive da comercialização desses resíduos. Nos países desenvolvidos, principalmente na Europa, existem problemas nítidos relacionados ao espaço físico para alocação de rejeitos. Em alguns países, os resíduos sólidos são transportados por longas distâncias até alcançar sua destinação final. Nos EUA, a previsão para 2005 é que a maioria dos aterros sanitários existentes tenha atingido sua capacidade máxima, ou esteja com especificações ultrapassadas em relação aos critérios de segurança exigidos ${ }^{[1]}$. No Brasil, uma nova política nacional de resíduos sólidos está sendo discutida na Câmara dos deputados, cujo relator principal é o deputado Emerson Kapaz. O importante nessa fase de implantação é estabelecer e assegurar metas sustentáveis que considerem as características e limitações intrínsecas do país ${ }^{[2]}$. Uma característica peculiar do Brasil é a presença de uma classe de trabalhadores de baixa renda que usufruem da atividade de coleta de resíduos recicláveis e acaba por inserir o país entre os maiores recicladores mun- diais. Essa parcela da população, de acordo com levantamento do Cempre (Compromisso Empresarial para a Reciclagem), atualmente representa cerca de 200 mil trabalhadores clandestinos ${ }^{[3]}$. Além disso, a maior parte do suprimento de resíduos do setor produtivo ${ }^{[4,5]}$ é proveniente da atividade de catadores. Dessa forma, a legalização, o incentivo e profissionalização dos catadores pela formação de cooperativas, além de inserir essa parcela da população dentro da sociedade economicamente ativa, pode contribuir como uma forma de viabilização da coleta seletiva em âmbito nacional ${ }^{[5]}$.

Aproximadamente $70 \%$ dos resíduos sólidos estão em aterros sanitários na Europa e EUA. No Japão, esta proporção está em torno de $40 \%$, pois grande parte vai para recuperação de energia. Este procedimento reduz o consumo de combustível e gás queimado para geração de energia e permite usar as quantidades economizadas de óleo para produção de plásticos virgens. Comparativamente, a Europa é o continente com maior índice de reciclagem de plásticos, tendo a Alemanha obtido os maiores níveis de reciclagem (32\% do total reciclado na Europa). Em segundo lugar aparecem os EUA com destaque para a reciclagem de PET.

Normalmente, os três principais meios utilizados para reduzir os resíduos sólidos aterrados em solo são: redução 
na fonte, reutilização, reciclagem de diferentes formas, incluindo a energética. Essas iniciativas, além de contribuir para não esgotar a capacidade dos aterros sanitários, contribuem para preservar os recursos naturais (energia elétrica, insumos primários, etc.); reduzir o consumo de energia, educar e conscientizar ambientalmente a população ${ }^{[2]}$. Especificamente para os plásticos, ainda contribuem para minimizar sua imagem de vilão ambiental causada por sua poluição visual nos grandes centros ${ }^{[3]}$ e sua taxa de crescimento expressiva nos aterros sanitários.

Como a incineração dos plásticos ainda está associada com riscos potenciais à saúde humana, a redução e a reciclagem constituem os principais focos das políticas de gerenciamento dos resíduos sólidos ${ }^{[1]}$. O alto custo operacional dos sistemas de coleta dos plásticos também confere, algumas vezes, maior viabilidade às recomendações de redução na fonte que a reciclagem em si desses resíduos. Entre os meios de alcançar a redução na fonte destaca-se o uso de embalagens mais duráveis e para maiores capacidades. No entanto, a redução na fonte pela substituição de materiais constitui uma alternativa secundária para os plásticos devido seu menor custo, praticidade, leveza e maior ganho em qualidade de vida em relação a potenciais materiais substituintes ${ }^{[1]}$. A natureza não inerte dos plásticos também inviabiliza o uso de embalagens retornáveis devido o uso indevido das mesmas pelos consumidores, tornando necessário processos de limpeza mais sofisticados e onerosos. Adicionalmente, pode-se levar em conta ainda que o número de ciclos de vida de uma garrafa retornável é finito.

\section{Sistemas de coleta - um ponto chave}

Conforme estudos realizados pela "Task Force", associação dos processadores de alimentos e da indústria de plásticos dos EUA, em 1995, o custo da coleta do resíduo doméstico era da ordem de US\$ 600-1.000 por tonelada. Já na Alemanha, o custo operacional do seu sistema de coleta de resíduos de embalagens plásticas, DSD (Dual System Deutschland), chega a $3000 \mathrm{DM} /$ ton, ou seja, 3 vezes maior que o custo das resinas virgens. Uma vez que a existência de um sistema de coleta de material constitui um primeiro passo para viabilizar atividades recicladoras, a oneração do setor público pode ser evitada tornando o setor produtivo responsável por seus resíduos. A criação de taxas para embalagens não recicláveis é um dos meios de promover maiores índices de reciclagem ${ }^{[6]}$. Algumas outras medidas que podem ser adotadas para não sobrecarregar o setor público são a imposição obrigatória do uso de reciclado em alguns setores, como obrigar o papel jornal conter $25 \%$ de papel reciclado ${ }^{[1]}$ e o incentivo ao uso de artigos exclusivos de material reciclado, sem a necessidade de licenciamento para quem os queira produzir $^{[3]}$. Esse raciocínio faz parte da logística reversa do retorno da embalagem final até o reciclador ${ }^{[3]}$.

Dessa forma, a tributação das indústrias por força política tem sido adotada no mundo para que as metas de reciclagem sejam atingidas a curto e médio prazo ${ }^{[7]}$. A viabilização do sistema de coleta também pode ser favorecida pela inserção de uma política de troca de embalagens por brinquedos, cupons com valor financeiro, ou material esportivo em comunidades carentes, por exemplo ${ }^{[8]}$. Uma iniciativa já implementada no Brasil é a aquisição e instalação de máquinas receptoras de material reciclável em grandes supermercados, cujo depósito da embalagem equivale a cupons de compra na respectiva loja ${ }^{[5]}$. Nessa cadeia, a participação do público tem sido sempre requisitada como parte fundamental do sistema de coleta, pois, de acordo com estudos realizados nos EUA, os consumidores finais consomem cerca de $75 \%$ da produção total de plástico na economia. No entanto, o desenvolvimento sustentável da reciclagem apenas será alcançado, se essa atividade se tornar de modo geral financeiramente rentável ${ }^{[7]}$.

Um ponto crítico para as legislações locais é a distribuição de responsabilidades pela redução dos resíduos de embalagens plásticas considerando 4 elementos da cadeia produtiva desse setor ${ }^{[9]}$ : o produtor da matéria prima; o processador; o engarrafador e o atravessador. Geralmente, devido a maior acessibilidade dos atravessadores ao consumidor final pode lhes ser atribuído um maior percentual de responsabilidade para que os objetivos impostos pela legislação sejam atingidos. Da mesma forma, os engarrafadores também apresentam grande potencial de responsabilidade por estarem também próximos aos consumidores e ditarem o "design" e especificações das embalagens. Outra contribuição importante que a cadeia produtiva pode promover é o uso de embalagens com menor número de resinas diferentes, o desenho de projetos que facilitem a separação de componentes das embalagens com resinas diferenciadas, evitando na medida do possível o uso de embalagens multicamadas ${ }^{[7]}$, adesivos, aditivos e rótulos nas embalagens $\mathbf{s}^{[1]}$.

A inserção do plástico reciclado no mercado consumidor também é outro aspecto chave para que metas de redução de resíduos sejam atingidas. Além disso, contribuem indiretamente para a redução no consumo geral dos plásticos, principalmente, se o crescimento do mercado da resina estiver estacionário. Esse efeito inclusive foi observado em projeções entre 1987 e 2005, para o consumo de plásticos em embalagens para bebidas carbonatadas nos EUA ${ }^{[10]}$.

Os plásticos constituem um dos principais focos entre todas as classes de materiais do RSU (Resíduo Sólido Urbano), pois são os que apresentam menores índices de reciclagem em todo o mundo ${ }^{[7,11]}$. Grande parte da dificuldade em reciclar plástico advém da fração significativa dos mesmos, cuja reciclabilidade é de antemão comprometida. Assim, considerando apenas a fração de plástico ecologicamente e economicamente reciclável, qualquer índice de reciclagem previamente estabelecido torna-se significativamente maior que qualquer valor nominal inicialmente estipulado ${ }^{[7]}$.

\section{Índices e metas de reciclagem}

Diante da necessidade iminente de reduzir o volume de resíduos nos RSU, na Europa foram estabelecidas por lei as metas de índices de recuperação e reciclagem para o setor de embalagens. Na Comunidade Européia (EC), a Diretiva 94/62/EC ${ }^{[2]}$ estabeleceu o prazo de junho de 2001 para que no mínimo 
$25 \%$ e no máximo $40 \%$ em massa das embalagens no lixo fossem recicladas e no mínimo $50 \%$ e no máximo de $65 \%$ fossem recuperadas. Além disso, cada material específico, deveria ter atingido uma taxa de reciclagem mínima de $15 \%$.

A forma sugerida para atingir esses objetivos foi a política dos 3 R's: reduzir, reutilizar e reciclar. Porém mesmo para os padrões europeus isto era um grande desafio; por exemplo, Tawfik et al. ${ }^{[12]}$ citaram que até 1993 apenas 5,6\% do plástico total descartado na EC era reciclado mecanicamente e $75,7 \%$ permaneciam nos aterros. Em 1994, esse índice de reciclagem aumentou para $6,3 \%$ da fração total de plástico pós-consumo, representando mais de $10^{6} \mathrm{t}$ de lixo reciclado. Esses índices, de acordo com a Associação de produtores de plásticos na Europa (APME), considerando apenas a fração de plástico presente no RSU, correspondiam a aproximadamente $20 \%$ da fração total de plástico recuperado por reciclagem e recuperação de energia. Essa última forma de recuperação inclusive ocupando um papel importante nos índices totais ${ }^{[1]}$. No mesmo período eram reciclados nos EUA apenas $773 \mathrm{kt}$ ( $\pm 4 \%$ de sua capacidade).

Como previsão otimista, era estimado que para 2001 aproximadamente $50 \%$ dos resíduos ainda continuariam dispostos em aterros na Europa ${ }^{[13]}$. Dados divulgados confirmam que essa previsão traçada na EC foi atingida com sucesso para a reciclagem de pape ${ }^{[14]}$. Com relação ao setor de embalagens plásticas, considerando a Alemanha, metas propostas também foram atingidas, ou no mínimo aproximadas, exceto para os materiais compósitos. Novas metas já foram inclusive traçadas na EC para 2006, onde cada tipo de plástico deve atingir índices de reciclagem de no mínimo $20 \%$, individualmente ${ }^{[14]}$.

Da mesma forma, em 2000, aproximadamente $11 \%$ da quantidade de plástico produzida nos EUA foram reciclados. Isto significa um grande avanço, pois apenas $1 \%$ dos resíduos plásticos eram reciclados em $1987^{[1]}$. Os EUA que atingiram níveis altíssimos de reciclagem de PET em 1995, atualmente enfrentam uma tendência à estagnação nesse índice de acordo com relatórios anuais emitidos pelo Conselho Americano de Plásticos (APC). No máximo, os índices de reciclagem aumentam acompanhando o crescimento de produção da resina ${ }^{[6]}$. Em 2001, não ocorreu um decréscimo nesses índices de reciclagem nos EUA apenas devido a absorção da demanda interna ociosa pelo mercado de exportações ${ }^{[6,15]}$.

No Brasil, $4 \%$ das embalagens plásticas e dos pneus presentes no resíduo sólido urbano são reciclados ${ }^{[4]}$. Porém, considerando os grandes centros urbanos (São Paulo, Rio de Janeiro, Porto Alegre e Salvador), os índices de reciclagem do material pós-consumo estão entre 9,4 e 19\%, de acordo com estudos entre 1999 e 2001 pela Plastivida e Maxiquim ${ }^{[16]}$. Os índices de reciclagem de PET no Brasil estão aumentando mesmo em relação aos percentuais de venda da resina virgem $^{[8]}$, sendo que este índice em 2001 esteve na ordem de $31 \%$ e é superior aos índices de países como EUA, Japão, França, Inglaterra, Itália e Alemanha ${ }^{[4,5]}$. É importante que o Brasil ocupe um papel relevante com relação aos índices de reciclagem de PET, pois ele constitui o terceiro maior mercado mundial de PET grau garrafa ${ }^{[3,17]}$.
A reciclagem no Brasil esbarra no suprimento incerto de matéria-prima, na ociosidade e na falta de logística. Por outro lado, apesar do sistema precário de coleta e disposição dos resíduos sólidos, a necessidade de aumentar a renda familiar associada à viabilidade econômica e à questão ambiental favorece as atividades de reciclagem ${ }^{[4]}$. A reciclagem de latas de alumínio é um exemplo bem sucedido e favorecido pela alta relação peso x volume dessas embalagens. Como as garrafas de PET são volumosas, esse fator acaba por limitar o crescimento exponencial de seus índices de reciclagem. Por outro lado, nos EUA, a ociosidade associada ao setor de reciclagem está mais vinculada ao baixo preço da resina virgem e a existências de brechas nas legislações estaduais ${ }^{[8]}$.

Resumidamente, as principais dificuldades inerentes do mercado do plástico reciclado são a ausência de comprometimento entre a demanda e o fornecimento das matérias-primas, o baixo custo das resinas virgens e a alta contaminação dos resídu$\mathrm{os}^{[2]}$. Esses fatores, na maioria, são responsáveis pela menor competitividade e qualidade final do plástico reciclado. Outro jargão que precisa ser vencido para que a divulgação do uso de material reciclado incentive as vendas e não tenha efeito contrário é sua visão pejorativa. Um exemplo típico da presença desse comportamento é a baixa divulgação do uso de reciclado em todo o revestimento de estofamento dos automóveis ${ }^{[3]}$.

Para que as metas de índices de reciclagem sejam atingidas, o uso de processos alternativos como super-limpeza, pirólise e reciclagem química serão necessários para agregar maior valor a resina reciclada ${ }^{[1]}$. A abertura e ampliação do mercado do plástico reciclado por meio de novas tecnologias e novos produtos contendo material reciclado também é um dos meios propostos para aumentar os índices de reciclagem dos plásticos. Na Europa, esse consenso já está inserido como um dos meios de viabilizar as metas de reciclagem estipuladas. Especificamente para o PET, o potencial máximo da reciclagem mecânica deve ser almejado, pois atualmente qualquer outra via de reciclagem é menos competitiva ${ }^{[7]}$.

\section{Reciclagem para aplicação em alimentos}

A reciclagem de plásticos visando o retorno para aplicações alimentícias era proibida mundialmente até a década de 90. Atualmente essa atividade consta como um dos principais desafios desse setor, pois representa todo um segmento de mercado a ser explorado. Além do que o setor de embalagens representa sozinho, aproximadamente $30 \% \mathrm{em}$ peso do consumo total de plásticos produzidos nos $\mathrm{EUA}^{[1]}$. As poliolefinas constituem a categoria de plástico dominante neste setor, compondo aproximadamente $75 \%$ do consumo de plástico dessa fatia de mercado ${ }^{[7]}$. Tecnicamente, o retorno desses resíduos é viável apenas ao processo de extrusão sopro e termoformagem, pois o processo de injeção exige menores viscosidades. Inclusive, um maior valor agregado ao reciclado pode ser alcançado pelo emprego de uma etapa adicional de separação das embalagens em cores claras e pigmentadas ${ }^{[18]}$. 
Por outro lado, mesmo representando apenas aproximadamente $3 \%$ do total de mercado de plásticos, ou seja, $10 \%$ do mercado de plásticos destinado ao setor de embalagens, as embalagens de PET constituem o centro da atenção dos recicladores. Entre os fatores que cooperam para este quadro estão: o custo relativamente alto da resina virgem, a alta competitividade de seus processos de reciclagem mecânica e $o$ alto valor agregado do reciclado cujo desempenho, dependendo da tecnologia aplicada, pode ser similar ao da resina virgem. Além disso, seu mercado é altamente especializado, sendo destinado basicamente ao setor de bebidas carbonatadas ${ }^{[1]}$. Tendências em ampliá-lo para outros nichos existem, como, por exemplo, para os mercados de embalagens de óleo comestível, água mineral, sucos, molhos, aguardentes, detergentes, condimentos, cosméticos e produtos químicos. Além de perspectivas para o PET abranger inclusive o mercado de embalagens para cerveja ${ }^{[3]}$.

Inicialmente, apenas os EUA e alguns países da Europa permitiram a aplicação do plástico reciclado para embalagens alimentícias. No Brasil, Chile, Austrália e mesmo em alguns países Europeus a aplicação do mesmo foi restringida ao contato indireto com alimentos, ou seja, em produtos multicamadas com uma camada de material descontaminado (alumínio, tratamentos superficiais, material virgem, etc.) em contato direto com o alimento ${ }^{[19]}$. Nesses casos, a proporção de reciclado nas embalagens é restringida.

Como não há nenhuma legislação específica para os materiais reciclados, eles são tratados impondo os mesmos limites de pureza e controle especificados para um material virgem, ou seja, não devem afetar a saúde dos consumidores. $\mathrm{Na}$ Europa, esses aspectos estão relacionados com a Diretiva 90/128/EEC ${ }^{[20]}$ e o artigo 2 da Diretiva 89/109/EEC ${ }^{[21]}$. Nos EUA, no Código de Leis Federais (CFR), a CFR $21^{[22,23]}$ trata os contaminantes presentes no resíduo plástico como aditivos para contato indireto com alimentos. No Brasil, de acordo com a resolução no 105 da ANVISA (Agência Nacional da Vigilância Sanitária) ${ }^{[24]}$, é proibido o uso de plástico reciclado para contato com alimentos, exceto no caso de materiais reprocessados no mesmo processo de transformação. Especificamente para aplicações de PET em bebidas não alcoólicas carbonatadas, a utilização de PET reciclado multicamada é permitida ${ }^{[25]}$.

Porém a pressão externa de algumas multinacionais com interesse no mercado brasileiro, o interesse comum do mercosul e a necessidade de colaborar para a ampliação dos índices de reciclagem tornaram possível uma abertura na legislação brasileira para eventuais empresas recicladoras que desejem exercer suas atividades no país para fins alimentícios. A resolução no 23 de 2000 estabelece a possibilidade de produzir PET reciclado para contato direto com alimentos, desde que a empresa requerente entre com um processo de petição junto a Vigilância Sanitária e prove que seu processo de reciclagem satisfaça os padrões internacionais de pureza adequada exigida pelo Codex Alimentarius (Código para Alimentos), ILSI (Instituto Internacional das Ciências da Vida) e FDA (Administração de Alimentos e Drogas). A abertura desse mercado no Brasil garante a valorização do produto final e conseqüentemente, a rentabilidade das atividades recicladoras. No entanto, uma conquista que ainda deve ser assegurada ao nosso plástico reciclado é a isenção de IPI durante sua comercialização ${ }^{[26]}$.

Os órgãos de referência nessa área nos EUA e na Europa são, respectivamente, a FDA e o ILSI. Essa volta das embalagens de alimentos ao seu próprio ciclo é considerada uma vitória, devido ao seu curto tempo de vida útil, o que as tornam responsáveis por aproximadamente $75 \%$ da fração de plásticos rígidos ${ }^{[27]}$. Há várias tecnologias disponíveis no mercado, as quais se concentram principalmente nos setores de reciclagem química e física (monocamada e multicamada).

$\mathrm{O}$ acesso a metodologias específicas para padronizar, controlar e avaliar processos de reciclagem quanto a sua capacidade de produzir reciclados, com pureza adequada para aplicações alimentícias, é obtido a partir de documentos elaborados pela $\mathrm{FDA}^{[28]}$, ILSI ${ }^{[29]}, \mathrm{BgVV}$ (Instituto de proteção à saúde dos consumidores e medicina veterinária) ${ }^{[30]}$ e PRTF/ SPI (Força tarefa para a reciclagem de plásticos/Sociedade industrial de plásticos) ${ }^{[31]}$. A necessidade de regulamentações específicas para a aplicação do plástico reciclado em contato com alimentos advém da probabilidade de absorção de produtos químicos tóxicos (armazenamento de pesticidas, produtos automotivos, solventes, agentes desinfetantes, a ação microbiológica dos resquícios dos alimentos, etc) durante a reutilização das embalagens para outros fins. Essa preocupação é pertinente devido as características de sorção e difusão de produtos químicos orgânicos nos plásticos e as baixas temperaturas dos seus processos de reciclagem. Por outro lado, aspectos relacionados à contaminação microbial podem ser desprezados, pois estes estão aderidos apenas superficialmente no plástico e podem ser desativados durante o processo de reciclagem pelo $\mathrm{pH}$ do meio de limpeza e pelas próprias temperaturas de processamento do polímero ${ }^{[28,32]}$.

Nesse contexto o aspecto que permite o retorno do plástico reciclado para contato direto com alimentos está relacionado ao nível máximo aceitável de um contaminante químico no plástico reciclado que ofereça risco mínimo à saúde pública e que não comprometa as propriedades organolépticas do produto envasado ${ }^{[33]}$. Como medidas ultra conservadoras, foram selecionadas substâncias carcinogênicas cuja exposição a curto prazo oferecesse um risco de contrair câncer menor que um em um milhão. A partir disso foi incluso um fator de segurança de 2000 vezes sobre o valor da concentração máxima permitida sob essas condições ${ }^{[19,34]}$. Mesmo para casos de exposição crônica, o valor sugerido inclui um fator de segurança de 200 vezes. Foi a partir dessas considerações que o princípio do "Threshold of regulation" (T/R) foi proposto. Através dele foi estabelecido $0,5 \mathrm{ppb}$ como limite de ingestão diária com risco negligenciáve ${ }^{[34,35,36]}$. Da mesma forma, qualquer aditivo usado em embalagens alimentícias que cause uma exposição ao consumidor em níveis inferiores àqueles previstos pelo $\mathrm{T} / \mathrm{R}$, não necessita de petição para ter seu uso aprovado.

Num estudo realizado por Pierce e colaboradores ${ }^{[37]}$ foram 
destacados três tipos de coleta: comum, específica com reembolso ao consumidor e extra-seletiva, sendo neste último caso selecionadas apenas garrafas sem adesivos e com base integral de PET. Nele foi verificado que após um processo convencional de reciclagem (lavagem, secagem e extrusão), os cromatogramas do PET reciclado a partir de coleta extra-seletiva e PET virgem foram bastante similares, destacando assim a importância deste sistema de coleta. Por outro lado, não foram observadas diferenças significativas entre o PET de coleta comum e coleta direta do consumidor, exceto com relação ao teor de PET não alimentício (10\%) incluso no primeiro sistema de coleta. Ambos apresentaram nível de impureza significativamente maior que o material virgem.

Durante a aprovação de um processo é importante dimensionar as tolerâncias dos seus parâmetros críticos em função de suas possíveis variações para determinar sua flexibilidade. Mesmo que este não atinja os níveis de remoção dos contaminantes exigidos, assumindo a hipótese de $100 \%$ de contaminação, argumentos podem ser utilizados de forma a aprová-lo. Entre alguns deles pode-se citar: blenda com material virgem, controle da fonte do resíduo, uso sob condições menos agressivas, barreira funcional, dados de migração, etc. Recomenda-se ainda que ele seja realizado com tolerâncias nos parâmetros críticos para evitar a necessidade de refazê-lo em função de variações nestes parâmetros ${ }^{[29,28]}$.

Historicamente para o PET, o primeiro processo de reciclagem mecânica com aprovação para aplicação em contato direto com qualquer classe de alimentos e sob qualquer condição de uso surgiu em 1994. A empresa requerente foi a Johnson Controls Inc. (Milwaukee - Manchester), cuja divisão foi posteriormente incorporada a Schmalbach-Lubeca AG (RatingenAlemanha $)^{[38-41]}$. Após esta data surgiram diversos outros processos de reciclagem mecânica e atualmente, os processos ditos "super-clean" são economicamente viáveis, porém ainda esbarram na qualidade e disponibilidade dos resíduos.

Ademais, a FDA tem diversos processos de reciclagem química e de aplicações em coextrudados (PET e PS virgem como barreira funcional) aprovados. Usos de reciclado também são permitidos em aplicações que envolvam contato limitado, temperatura ambiente ou refrigerada, razão alta entre massa de alimento embalado e área superficial de contato, alimentos com embalagem própria ou que devam ser lavados antes do consumo. Como exemplos são citados: embalagens de ovos de PS reciclado, sacolas de mercearia, engradados de PE e PP e cestas de PET reciclados para transporte e embalagem de frutas e verduras frescas ${ }^{[42]}$.

\section{Conclusões}

Independente das peculiaridades regionais, o gerenciamento do resíduo sólido é de fundamental importância para a população mundial e deve ser desenvolvido para que seja um sistema auto-sustentável. A curto e médio prazo há uma tendência a forçar o funcionamento operacional de uma logística reversa por meio de Leis específicas e subsídios, a qual em longo prazo deve se tornar rentável.
Nesse contexto, o desenvolvimento de tecnologias inovadoras e de novos mercados para o plástico reciclado assume um papel importante para o gerenciamento de seus resíduos. Particularmente, no Brasil, apesar do estado incipiente do sistema de coleta de material, há a possibilidade de criar um sistema de coleta inovador, eficiente e de baixo custo a partir da centralização dos esforços individuais de catadores. Paralelamente, o comprometimento entre custo de mercado e aplicação é imprescindível para sua viabilização. Além disso a flexibilidade à adequação das flutuações de mercado (produção e demanda) e preços são igualmente importantes ${ }^{[2]}$.

\section{Agradecimentos}

Os autores agradecem a FAPESP pelo apoio à pesquisa em desenvolvimento na área de PET reciclado para contato com alimentos.

\section{Referências Bibliográficas}

1. Duchin, F. \& Lange, G. M. - Structural Changes and Economic Dynamics, 9, p.307 (1998).

2. Daskalopoulos, E.; Badr, O. \& Probert, S. D. - Applied Energy, 58, p.209 (1997).

3. Borges, A. - Gazeta Mercantil, p.C-6, 24 de mar. (1999).

4. EM busca de soluções. Embanews, p.46, jan. (2002).

5. Gimenez, K. - Plásticos em Revista, p.22, maio (2002).

6. Toloken, S. Plásticos em revista, p.38, nov. (2002).

7. Dent, I. - Plastic Packaging Recycling, 3p. (1999).

8. FLANCO exposto. - Plásticos em revista, p.28, jun. (2001).

9. Tombs, G. - Plastic Packaging Recycling, 3p. (1999).

10 - Esposito, F. - Plásticos em Revista, p.28, maio (2001).

11. RECYCLING - the debate continues. Warmer Bulletin, p.52, jan. (1997).

12. Tawfik, M. S.; Devlieghere, F.; Steurbaut, W. \& Huyghebaert, A. - Acta Alimentaria, 26, p.219 (1997).

13. Dennison, M. T. \& Mennicken, T.- "Plastics recycling in Europe", in: Proceedings of PACIA CONVENTION, Brisbane (1996).

14. Onusseit, H. - "Sustainable development during production and use of tape", in: Proceedings of $1^{\text {st }}$ AFERA Technical Seminar, Düsseldorf (2002).

15. Toloken, S. - Plásticos em Revista, p.33, set. (2002).

16. Gimenez, K. - Plásticos em Revista, p.30, Jun. (2002).

17. Mancini, S. D. \& Zanin, M. - Plástico Industrial, p.118, set. (2000).

18 - Haigh, B. - Plastic Packaging Recycling, 4p. (1999). 
19. Bayer, F. L. - Food Additives and Contaminants, 14, p. 661 (1997).

20. Comunidade Européia. Council. Directive 90/128/EEC. - Official Journal of the European Communities, $\mathrm{n}^{\underline{0}}$ L349, p.26, Brussels (1990).

21. Comunidade Européia. Council. Directive 89/109/EEC. - Official Journal of the European Communities, $\mathrm{n}^{-}$ L40, p. 38, Brussels (1989).

22. Estados Unidos da América. Food and Drug Administration. Code of Federal Regulations, Título 21, partes 174, 175, 177 e 178. - Disponível em: <http:/ /www.gpo.gov> Acesso em: 17 out 2000.

23. Störmer, A. \& Welle, F. - Materials/Recycle, 1, p.8 (2000).

24. Brasil. Agência Nacional de Vigilância Sanitária. Resolução no 105 - Diário Oficial da República Federativa do Brasil, Seção 1, 21, Brasília-DF, 20 maio (1999).

25. Brasil. Agência Nacional de Vigilância Sanitária. Portaria no 987 - Diário Oficial da República Federativa do Brasil, Brasília-DF, 9 dez. (1998). Disponível em: $<$ http://www.dou.gov.br/materiais/do $1 /$ do1msasvs19981209173557.htm>. Acesso em: 23 jul 1999.

26. Sette, A. "A reciclagem de PET no Brasil", in: Anais do Seminário Internacional de Reciclagem de PET Pósconsumo para Contato com Alimentos, Campinas-SP, set. (2003).

27. Mancini. S.; Santos, A. S. F. S.; Manrich, S. \& Zanin, M. - Pack, p.36 (2001).

28. Estados Unidos da América. Food and Drug Administration. "Points to consider for the use of recycled Plastics in Food Packaging: Chemistry Considerations". Disponível em: <http:// www.fda.gov> Acesso em: 10 Maio 2003.

29. International Life Sciences Institute. Guidelines for recycling of plastics for food contact use. Brussels, 22p. (1997).

30. Bündesinstitut für Gesundheitlichen Verbraucherschutz und Veterinärmdizin. "Use of mechanically recycled plastic made from polyethylene terephthalate (PET) for the manufacture of articles coming into contact with food" (2001).

31. Plastics Recycling Task Force; National Food Processors Association; The Society Of The Plastics Industry, Inc. "Guidelines for the safe use of recycled plastics for food packaging applications" (1995).

32. Devlieghere, F. \& Huyghebaert, A. - LebensmittelWissenschafts und -Technologie, 30, p.62 (1997).

33. Kuznesof, P. M. \& Vanderveer, M. C. "Recycled plastics for food-contact applications", in : Plastics, rubber, and paper recycling, cap. 32, American Chemical Society, New York (1995).

34. Begley, T. H. - Food Additives and Contaminants, 14, p.545 (1997).

35. Estados Unidos da América. Food and Drug Administration. Code of Federal Regulations, 58, p.52719 (1993).

36. Estados Unidos da América. Food and Drug Administration. Code of Federal Regulations, 60, p.36582 (1995).

37. Pierce, D. E.; King, D. B. \& Sadler, G. D. "Analysis of Contaminants in recycled Poly(ethylene terephthalate) by thermal Extraction Gas Chromatography - Mass Spectroscopy", in: Plastics, rubber, and paper recycling, cap. 37, American Chemical Society, New York (1995).

38. Ford, T. - Plastics News, p.2, set. (1994).

39. "SUPER-CLEAN" processes recycles PET. Scrap Processing and Recycling, p.28, jan.-fev. (1995).

40. Smith, S. S. - Plastics News, p.5, mar. (1997).

41. Food and Drug Administration. Center for Food Safety \& Applied Nutrition. Recycled plastics in food packaging. Disponível em: <http://www.fda.gov> Acesso em: 20 ago. (2000).

42. Thorsheim, H. R. \& Armstrong, D. J. - Chemtech, p.55, ago. (1993).

Enviado: 04/12/03

Aprovado: $15 / 06 / 04$ 